\title{
Binary NiCu layered double hydroxide nanosheets for enhanced energy storage performance as supercapacitor electrode
}

\author{
Teng Wang, Shengli Zhang and Hongxia Wang*
}

Owing to the high power density and long-term stability characteristics, supercapacitors (SCs), also called electrochemical capacitors, have attracted great interests as one of the most efficient electrical energy storage devices [1]. According to the charge storage mechanism of the electrode, SCs are classified into electric double layer capacitors (EDLC) which store charges via static electrolyte ion adsorption/desorption, and pseudo-capacitors (PSC) which involve a faradaic redox reaction process. PSCs have attracted lots of attention recently because of their advantage of higher energy storage ability than EDLC to meet broader applications [2]. The energy density of a PSC strongly depends on the nature of the electrode material and the material morphology.

Candidate materials including transition metal oxides/ hydroxides/chalcogenides/phosphides, conductive polymers, and MXene materials have been reported to possess good pseudocapacitive properties [3-9]. Specially, PSCs based on nickel hydroxide/layered double hydroxide (LDH) have been investigated extensively due to their high theoretical capacitance [10-12]. Nevertheless, experimentally the electrochemical properties of NiLDH such as specific capacitance and rate capability are normally unsatisfactory due to the poor conductivity and fragile crystalline structure of the material. One approach to solve this problem is through introduction of additional metal ions such as cobalt and aluminium to make binary LDH [13-16]. As an earth-abundant element, $\mathrm{Cu}$ based hydroxide materials recently received limited interest in application in SCs [17-20]. For example, Pramanik et al. [20] reported a $\mathrm{Cu}(\mathrm{OH})_{2} @ \mathrm{RGO}$ composite, which exhibited a specific capacitance of $602 \mathrm{Fg}^{-1}$ at a small current density of $0.2 \mathrm{~A} \mathrm{~g}^{-1}$. However, the materials normally show an unsatisfied energy storage ability including a low specific capacitance and low conductivity. Zheng et al. [21] recently reported $\mathrm{NiCu}$ carbonate hydroxide nanowire arrays formed on $\mathrm{Cu}$ foam. The material exhibited a promising supercapacitive performance $\left(971 \mathrm{~F} \mathrm{~g}^{-1}\right.$ at $\left.1 \mathrm{~A} \mathrm{~g}^{-1}\right)$. Nevertheless, the capacitance is still unsatisfactory which is even lower than single metal NiLDH materials [11]. Moreover, the rigidity of the $\mathrm{Cu}$ foam limits its application in wearable devices, which has recently been regarded as one of the main developing directions for advanced SCs [22-24]. Clearly more indepth research of $\mathrm{NiCu} \mathrm{LDH}$ is needed to explore its potential as electrode material for SC application.

Herein, we demonstrate a facile way to enhance the electrochemical properties of NiLDH nanosheet arrays which was directly grown on carbon fiber cloth (CFC) through incorporation of $\mathrm{Cu}$ via a one-step solvothermal method. The as-prepared NiCuLDH material demonstrated significantly increased specific capacitance $\left(1953.5 \mathrm{~F} \mathrm{~g}^{-1}\right.$ at $\left.0.5 \mathrm{~A} \mathrm{~g}^{-1}\right)$, excellent rate stability and conductivity.

The NiCuLDH material was synthesized using the modified solvothermal method we reported recently [13]. In this one-step reaction, 2-methylimidazole (MIM) and pure methanol were used as surfactant and solvent respectively. The NiCuLDH with precursor ratio of $\mathrm{Ni} /$ $\mathrm{Cu}=1$ (named $\mathrm{NiCuLDH}(10-10)$ ) was firstly made and used for characterization. Fig. 1a reveals the field emission scanning electron microscope (FESEM) image of bare carbon fibers which show a smooth surface. After the solvothermal reaction, the carbon fiber is uniformly

School of Chemistry, Physics and Mechanical Engineering, Science and Engineering Faculty, Queensland University of Technology, Brisbane, QLD 4001, Australia

* Corresponding author (email: hx.wang@qut.edu.au) 

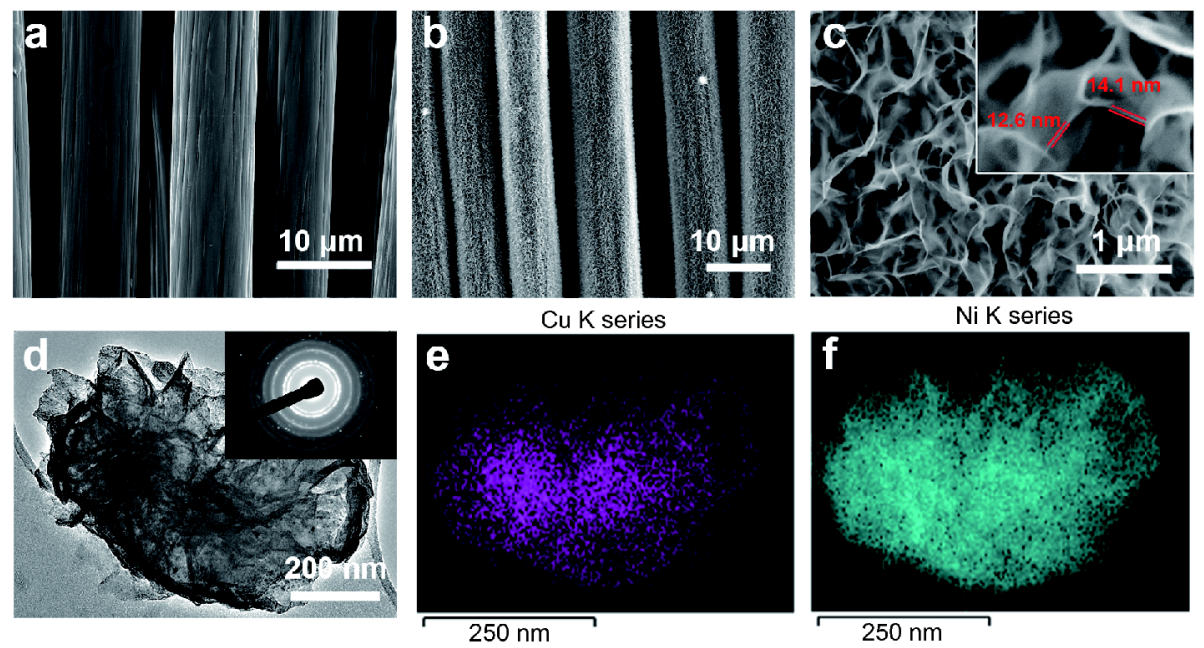

Figure 1 (a) FESEM image of bare CFC; FESEM images (b, c), TEM images (d), and STEM element distribution images for Cu (e) and Ni (f) of $\mathrm{NiCuLDH}(10-10)$; the inset of (c) is the enlarged FESEM image and the inset in (d) is the SAED pattern of NiCuLDH(10-10).

coated with a porous layer of active material (Fig. 1b). The enlarged FESEM image (Fig. 1c) confirms that the layer consists of ultrathin nanosheets which are interconnected to form hierarchical porous structure. The open pores have sizes from 10 to over $200 \mathrm{~nm}$ while the thickness of the nanosheet is only around $10-20 \mathrm{~nm}$ (inset of Fig. 1c). The porous structure is known to favor efficient electrolyte ion transport and shortening electrolyte diffusion length during charge/discharge process [13]. The transmission electron microscope (TEM) image of $\mathrm{NiCuLDH}(10-10)$ (Fig. 1d) further confirms the thin thickness of nanosheets and interconnected $3 \mathrm{D}$ porous nanostructure. Its selected area electron diffraction (SAED) pattern (inset of Fig. 1d) demonstrates the multicrystalline nature of the material and the EDS spectrum (Fig. S1), which confirms the sample is composed of C, O, $\mathrm{Cl}, \mathrm{Ni}$ and $\mathrm{Cu}$ with the atomic ratio of $\mathrm{Ni} / \mathrm{Cu}=7.6$. The detected $\mathrm{Al}$ signal should come from the FESEM sample stage. The atomic ratio value is much higher than the $1: 1$ ratio designed in the precursor, indicating a faster reaction rate of $\mathrm{Ni}^{2+}$ ion and the difficulty of the formation of $\mathrm{Cu}$ hydroxide material. It is worth noting that the element composition can be easily tuned by changing the precursor ratio. The mapping of the distribution of elements in the sample measured by scanning transmission electron microscope (STEM) (Fig. 1e and f) demonstrates that $\mathrm{Ni}$ is evenly dispersed over the whole material area while $\mathrm{Cu}$ mainly appears in the center area. This indicates that $\mathrm{Cu}$ mainly exists at the inner layer of the film. This unique composition distribution is beneficial to exposing more active Ni reaction sites, favoring the enhancement of energy storage ability.

The X-ray diffraction (XRD) patterns of CFC, NiLDH and $\mathrm{NiCuLDH}(10-10)$ are depicted in Fig. 2a. Due to the thin thickness of active materials, the XRD patterns of $\mathrm{NiLDH}$ and $\mathrm{NiCuLDH}(10-10)$ contain strong diffraction peaks of the CFC substrate at $25.5^{\circ}, 43.3^{\circ}$, and $53.5^{\circ}$ which are assigned to the (002), (101), and (004) facets of CFC (ICDD: 00-046-1487). Compared with NiLDH, no extra diffraction peaks appear in the XRD pattern of $\mathrm{NiCuLDH}$ (10-10), demonstrating that the incorporation of $\mathrm{Cu}$ does not significantly change the material structure. The peaks at $10.7^{\circ}, 33.2^{\circ}$ and $58.6^{\circ}$ can be indexed to the (003), (101), and (110) facets of brucite like LDH structure [11,25-27]. It should be noted that the adding of $\mathrm{Cu}$ caused a slight crystal structure disorder according to the XRD result. The intensity of (003) facet of as-prepared $\mathrm{NiCuLDH}(10-10)$ was dramatically reduced compared with that of the pristine NiLDH. The surface chemistry information was analyzed by X-ray photoelectron spectroscopy (XPS). Specifically, the high resolution XPS (HRXPS) plots of Ni 2p of both NiLDH and NiCuLDH (10-10) (Fig. 2b) indicate a typical $\mathrm{Ni}^{2+}$ chemical state [28]. Compared with NiLDH, the binding energy of Ni 2p in $\mathrm{NiCuLDH}(10-10)$ shifts to a higher position, suggesting a relatively higher oxidation state of $\mathrm{Ni}$ [13]. Therefore, $\mathrm{Cu}$ incorporation induced a positive charge shift of $\mathrm{Ni}^{2+}$, which might contribute to an enhanced charge storage ability. The HRXPS plot of O 1s of both NiLDH and $\mathrm{NiCuLDH}(10-10)$ are fitted into three peaks (Fig. 2c). For $\mathrm{NiCuLDH}(10-10)$, the peaks at 530.3, 531.0, and $532.1 \mathrm{eV}$ are assigned to $\mathrm{M}-\mathrm{O}-\mathrm{M}, \mathrm{M}-\mathrm{OH}$ and $\mathrm{H}-\mathrm{O}-\mathrm{H}$ 

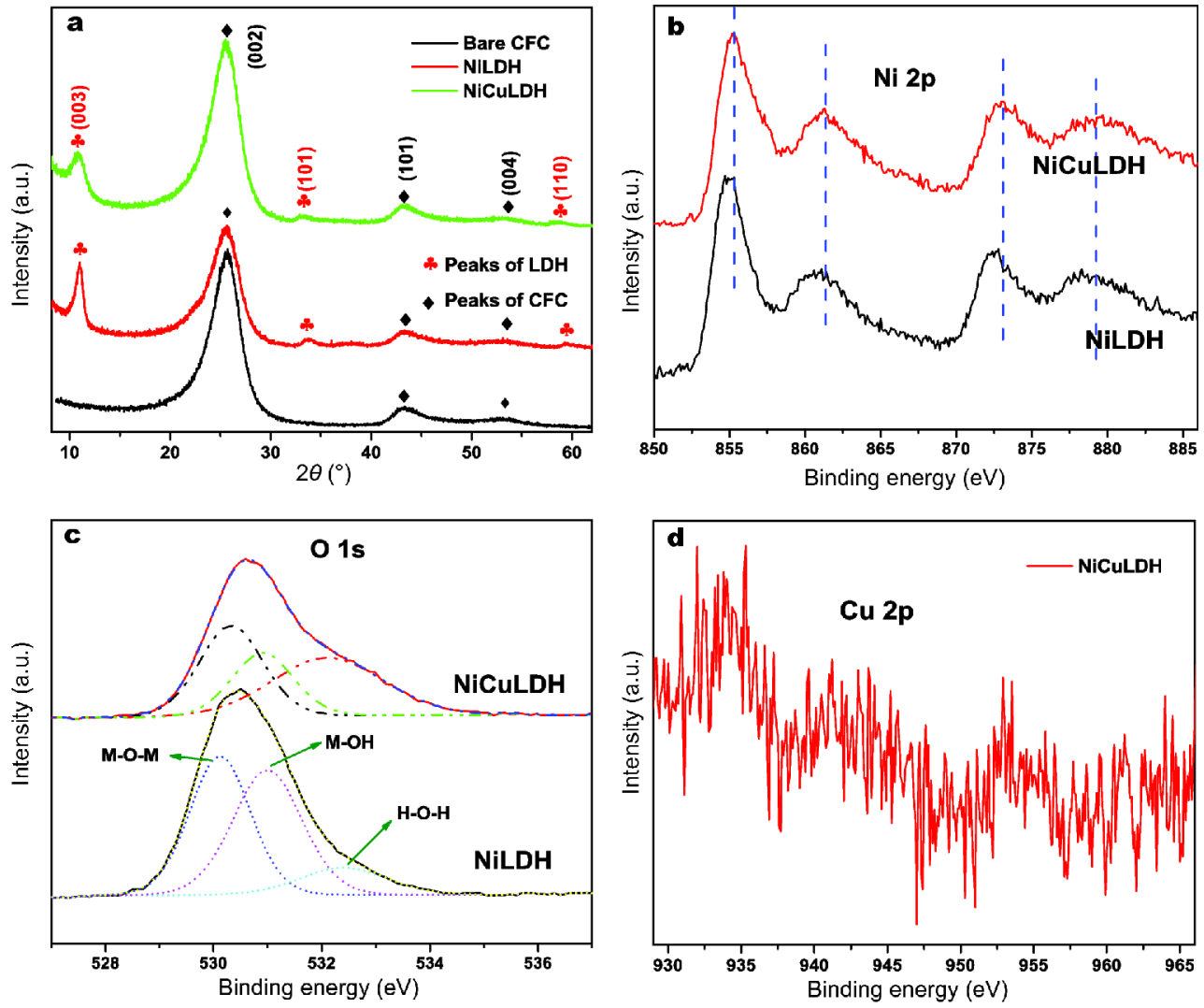

Figure 2 (a) XRD patterns of bare CFC, NiLDH, and NiCuLDH (10-10); HRXPS plots of Ni 2p (b) and O 1s (c) of NiLDH and NiCuLDH(10-10); and HRXPS plot of $\mathrm{Cu} 2 \mathrm{p}$ (d) of $\mathrm{NiCuLDH}(10-10)$.

(where $\mathrm{M}$ denotes metal ion) respectively $[29,30]$. The considerably increased intensity of $\mathrm{H}-\mathrm{O}-\mathrm{H}$ peak compared to that in NiLDH indicates that the material contains more water molecules. Only a weak signal of $\mathrm{Cu} 2 \mathrm{p}$ is observed in the HRXPS plot of $\mathrm{NiCuLDH}(10-10)$ (Fig. $2 \mathrm{~d}$ ) indicating that only few $\mathrm{Cu}$ atoms are exposed at the surface, which is in accordance with the STEM results (Fig. 1e). The binding energy at $934.2 \mathrm{eV}$ for $\mathrm{Cu} 2 \mathrm{p}_{3 / 2}$ suggests a 2+ valence state of copper ion [21,29].

The electrochemical performance of $\mathrm{NiLDH}$ and $\mathrm{Ni}$ $\mathrm{CuLDH}$ were evaluated through a 3-electrode set-up consisting of as-prepared active materials as working electrode, a Pt foil as counter electrode and $\mathrm{Hg} / \mathrm{HgO}$ reference electrode in $2 \mathrm{~mol} \mathrm{~L}^{-1} \mathrm{KOH}$ aqueous electrolyte. In order to optimize the supercapacitive property of the $\mathrm{NiCuLDH}$ material, a series of materials with different $\mathrm{Ni} / \mathrm{Cu}$ ratios in the precursor including $\mathrm{NiCuLDH}(10-3)$ $(\mathrm{Ni} / \mathrm{Cu}=10: 3), \mathrm{NiCuLDH}(10-7)(\mathrm{Ni} / \mathrm{Cu}=10: 7)$, and $\mathrm{Ni}-$ $\mathrm{CuLDH}(7-10)(\mathrm{Ni} / \mathrm{Cu}=7: 10)$ were also synthesized. The synthesis of pure CuLDH was also attempted. However, no product was obtained in the reaction condition when pure $\mathrm{Cu}$ precursor was used. This may be because of the lack of base additives and weak interaction reaction between $\mathrm{Cu}^{2+}$ and 2-methylimidazole complex [13].

As shown in Fig. S2, the cyclic voltammetry (CV) curve of NiLDH material at a scan rate of $2 \mathrm{mV} \mathrm{s}^{-1}$ shows two pairs of redox peaks with the oxidation peaks at $0.49 \mathrm{~V}$ and $0.54 \mathrm{~V}(v s . \mathrm{Hg} / \mathrm{HgO})$ and reduction peaks at 0.30 and $0.26 \mathrm{~V}(v s . \mathrm{Hg} / \mathrm{HgO})$ respectively, which corresponds to the redox reaction of $\mathrm{Ni}^{2+} / \mathrm{Ni}^{3+}$ [31-33]. The reaction mechanism can be described as Equation (1):

$$
\mathrm{Ni}(\mathrm{OH})_{2}+\mathrm{OH}^{-} \rightarrow \mathrm{NiOOH}+\mathrm{H}_{2} \mathrm{O}+\mathrm{e}^{-} .
$$

It is noted that the CV shapes of NiLDH material are twisted seriously as the scan rate increases from 2 to $30 \mathrm{mV} \mathrm{s}^{-1}$, suggesting a poor reversibility of the material due to sluggish kinetics of charge transport. Fig. 3a shows the CV plots of NiLDH and NiCuLDH with different Ni/ $\mathrm{Cu}$ precursor ratios at a scan rate of $10 \mathrm{mV} \mathrm{s}^{-1}$. Compared to NiLDH, a less shift of the redox reaction peaks is found with all the NiCuLDH materials. This suggests enhanced redox reaction kinetics of the latter, resulting in better 

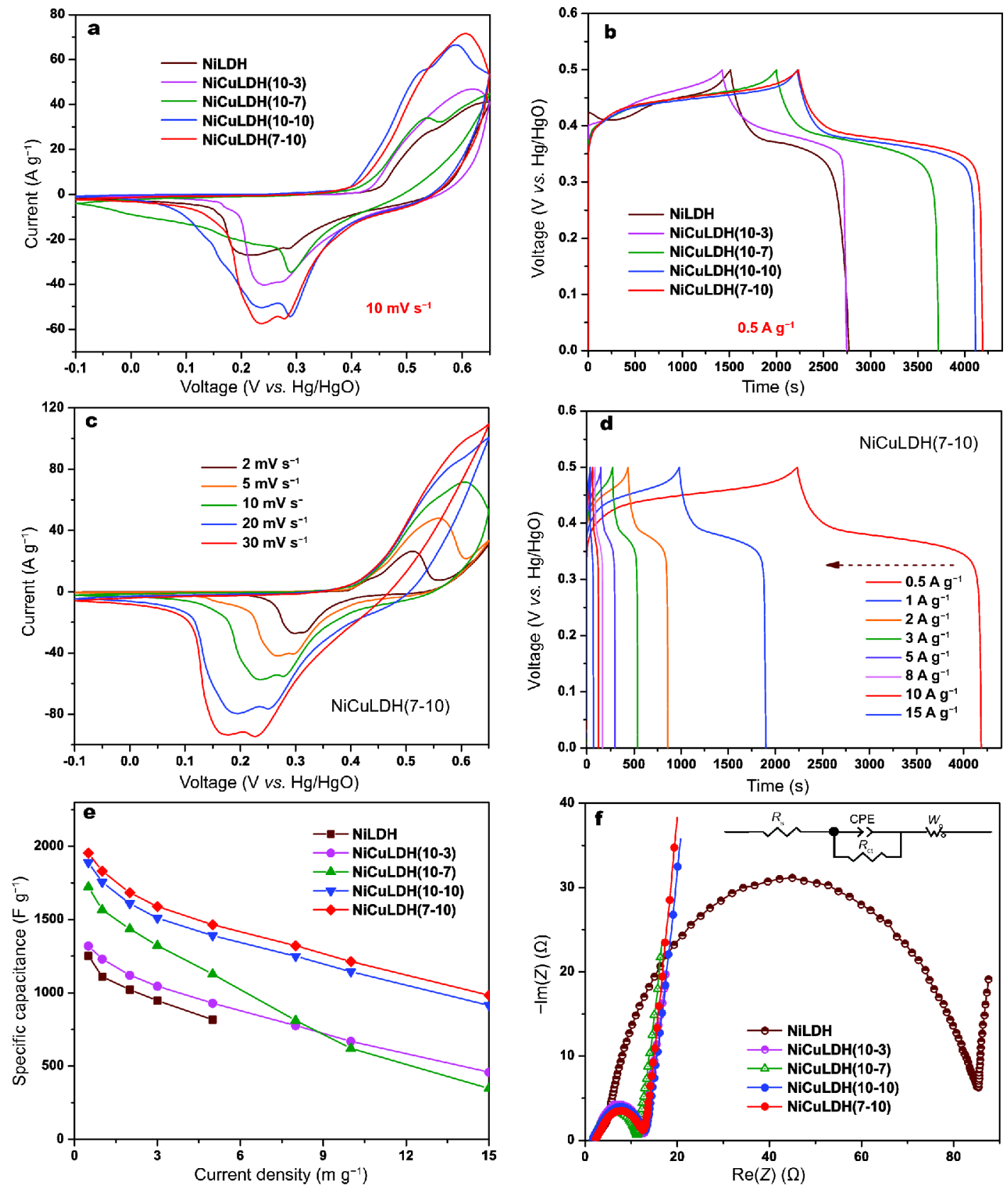

Figure $3 \mathrm{CV}$ (a) and CDC plots (b) of NiLDH and NiCuLDH with different Ni/Cu ratios; $\mathrm{CV}$ at different scan rates (c) and GCD plots at different current densities (d) of NiCuLDH(7-10); capacitance (e) and EIS (f) comparison between NiLDH and NiCuLDH with different Ni/Cu ratios; the inset in (f) is the equivalent circuit.

reversibility. Meanwhile, at the same scan rate, the current density of $\mathrm{NiCuLDH}$ increases continuously along with the higher content of added $\mathrm{Cu}$. The $\mathrm{NiCuLDH}(7-$ 10) with the highest $\mathrm{Cu}$ content shows a nearly 2 -fold higher current density peak than that of NiLDH, reflecting a much higher energy storage capability. The comparison of galvanic charge/discharge (GCD) plot
(Fig. 3b) of $\mathrm{NiLDH}$ and $\mathrm{NiCuLDH}$ with different $\mathrm{Ni} / \mathrm{Cu}$ precursor ratios at a current density of $0.5 \mathrm{~A} \mathrm{~g}^{-1}$ further proves the faradaic charge transport behavior of all the materials. The much longer charge/discharge time of $\mathrm{NiCuLDH}$ compared to NiLDH indicates a higher specific capacitance. Similarly, NiCuLDH(7-10) exhibits the longest charge/discharge time, suggesting the highest 
Table 1 Comparison of electrochemical performance of as-prepared NiCuLDH with the materials reported in literature

\begin{tabular}{|c|c|c|c|c|c|}
\hline Active materials & Voltage window (V) & Specific capacitance & Rate capability & Cyclic stability & Ref. \\
\hline $\mathrm{Cu}(\mathrm{OH})_{2}-\mathrm{rGO}$ & 0.47 & $\begin{array}{l}602 \mathrm{~F} \mathrm{~g}^{-1} \text { at } 0.2 \mathrm{~A} \mathrm{~g}^{-1} \text { in } \\
1 \mathrm{~mol} \mathrm{~L}^{-1} \mathrm{KOH}\end{array}$ & $53 \%$ at $10 \mathrm{~A} \mathrm{~g}^{-1}$ & $\begin{array}{l}89 \% \text { at } 5 \mathrm{~A} \mathrm{~g}^{-1} \\
\text { after } 5000 \text { cycles }\end{array}$ & [20] \\
\hline $\mathrm{Cu}(\mathrm{OH})_{2}$ nanorods & 0.55 & $\begin{array}{c}1.747 \mathrm{~F} \mathrm{~cm}^{-2} \text { at } 2 \mathrm{~mA} \mathrm{~cm}^{-2} \text { in } \\
5 \mathrm{~mol} \mathrm{~L}^{-1} \mathrm{NaOH}\end{array}$ & $88.3 \%$ at $20 \mathrm{~mA} \mathrm{~cm}^{-2}$ & $\begin{array}{l}97.3 \% \text { after } 5000 \\
\text { cycles }\end{array}$ & {$[18]$} \\
\hline $\mathrm{Cu}(\mathrm{OH})_{2}$ nanobelt arrays & 0.5 & $\begin{array}{c}217 \mathrm{mF} \mathrm{cm}^{-2} \text { at } 0.5 \mathrm{~mA} \mathrm{~cm}^{-2} \text { in } \\
1 \mathrm{~mol} \mathrm{~L}^{-1} \mathrm{NaOH}\end{array}$ & $61 \%$ at $2 \mathrm{~mA} \mathrm{~cm}^{-2}$ & $\begin{array}{c}90 \% \text { after } 3000 \\
\text { cycles at } 2 \mathrm{~mA} \mathrm{~cm}^{-2}\end{array}$ & [19] \\
\hline $\mathrm{Cu}(\mathrm{OH})_{2} \mathrm{CO}_{3}$ nanowires & 0.6 & $\begin{array}{c}971 \mathrm{~F} \mathrm{~g}^{-1} \text { at } 1 \mathrm{~A} \mathrm{~g}^{-1} \text { in } \\
6 \mathrm{~mol} \mathrm{~L}^{-1} \mathrm{KOH}\end{array}$ & $69.5 \%$ at $10 \mathrm{~A} \mathrm{~g}^{-1}$ & $\begin{array}{l}91.5 \% \text { after } 3000 \\
\text { cycles at } 5 \mathrm{~A} \mathrm{~g}^{-1}\end{array}$ & {$[21]$} \\
\hline $\mathrm{Cl}^{-}$intercalated $\alpha-\mathrm{Ni}(\mathrm{OH})_{2}$ & 0.45 & $\begin{array}{c}1494 \mathrm{~F} \mathrm{~g}^{-1} \text { at } 1 \mathrm{~A} \mathrm{~g}^{-1} \text { in } \\
1 \mathrm{~mol} \mathrm{~L}^{-1} \mathrm{KOH}\end{array}$ & $30 \%$ at $8 \mathrm{~A} \mathrm{~g}^{-1}$ & $\begin{array}{l}81.9 \% \text { after } 500 \\
\text { cycles at } 4 \mathrm{~A} \mathrm{~g}^{-1}\end{array}$ & [14] \\
\hline$\beta-\mathrm{Ni}(\mathrm{OH})_{2}$ & 0.5 & $\begin{array}{c}880 \mathrm{~F} \mathrm{~g}^{-1} \text { at } 2 \mathrm{~A} \mathrm{~g}^{-1} \text { in } \\
1 \mathrm{~mol} \mathrm{~L}^{-1} \mathrm{NaOH}\end{array}$ & $54 \%$ at $20 \mathrm{~A} \mathrm{~g}^{-1}$ & $\begin{array}{l}60 \% \text { after } 500 \\
\text { cycles at } 5 \mathrm{~A} \mathrm{~g}^{-1}\end{array}$ & [35] \\
\hline $\mathrm{NiCuLDH}(7-10)$ & 0.5 & $\begin{array}{c}1953.5 \mathrm{~F} \mathrm{~g}^{-1} \text { at } 0.5 \mathrm{~A} \mathrm{~g}^{-1} \text { in } \\
2 \mathrm{~mol} \mathrm{~L}^{-1} \mathrm{KOH}\end{array}$ & $75 \%$ at $5 \mathrm{~A} \mathrm{~g}^{-1}$ & $\begin{array}{l}35 \% \text { after } 500 \\
\text { cycles at } 5 \mathrm{~A} \mathrm{~g}^{-1}\end{array}$ & This work \\
\hline
\end{tabular}

charge storage ability. The CV plots under various scan rates and GCD plots at different current densities of $\mathrm{NiCuLDH}(7-10)$ are shown in Fig. $3 \mathrm{c}$ and $\mathrm{d}$, confirming its high reversibility and high rate ability. It is noted that the NiLDH shows no charge storage ability when the charge/discharge current density increases to $8 \mathrm{~A} \mathrm{~g}^{-1}$ with the discharge time of $0 \mathrm{~s}$ (Fig. S2) while the $\mathrm{NiCuLDH}(7-$ 10) still exhibits very good discharge capability even at $15 \mathrm{~A} \mathrm{~g}^{-1}$ under the potential window of $0.5 \mathrm{~V}$, suggesting a much improved rate capability of $\mathrm{NiCuLDH}(7-10)$. This should be because of the much improved conductivity of $\mathrm{NiCuLDH}$ which will be discussed later.

Fig. 3e presents the specific capacitance of both NiLDH and NiCuLDH materials based on their GCD plots using the equation $(\mathrm{C}=I t / m \Delta U$, where $I$ is the current density $\left(\mathrm{A} \mathrm{g}^{-1}\right), t$ is the discharge time (s), $m$ is the mass loading of active material and $\Delta U$ is the potential window $(\mathrm{V}))$. It can be clearly seen that the incorporation of $\mathrm{Cu}$ significantly enhances the SC performance of pristine $\mathrm{NiLDH}$ material and the higher content of $\mathrm{Cu}$ results in a higher capacitance. Among the NiCuLDH materials, NiCuLDH(7-10) exhibits the highest SC performance with a considerably high specific capacitance of $1953.5 \mathrm{~F} \mathrm{~g}^{-1}$ which is $50 \%$ higher than the pristine NiLDH (1252.9 $\mathrm{F} \mathrm{g}^{-1}$ ) at $0.5 \mathrm{~A} \mathrm{~g}^{-1}$. By increasing the current density 10 times to $5 \mathrm{~A} \mathrm{~g}^{-1}$, the capacitance of the $\mathrm{NiCuLDH}(7-10)$ still remains at $1465.0 \mathrm{~F} \mathrm{~g}^{-1}$, leading to the retention rate of $75 \%$. In contrast, the specific capacitance of $\mathrm{NiLDH}$ reduces dramatically to $817 \mathrm{~F} \mathrm{~g}^{-1}$ at $5 \mathrm{~A} \mathrm{~g}^{-1}$ with merely a $65 \%$ retention rate. Table 1 compares the electrochemical performance of the as-prepared $\mathrm{NiCuLDH}$ material with other similar reported materials. It clearly shows that the as-prepared $\mathrm{NiCuLDH}(7-10)$ exhibits much higher capacitance and competitive rate capability than other $\mathrm{Ni}$ and $\mathrm{Cu}$ based hydroxide materials reported previously
[17-20,34]. Further measurement by electrochemical impedance spectrum (EIS) (Fig. 3f) reveals that all the $\mathrm{Cu}$ introduced NiLDH materials have a much reduced series resistance $\left(R_{\mathrm{s}}\right)$ and charge transfer resistance $\left(R_{\mathrm{ct}}\right)$. For the optimum NiCuLDH(7-10) sample, the $R_{\mathrm{s}}$ decreased from $3.1 \Omega$ for single $\mathrm{NiLDH}$ to $1.8 \Omega$ whereas $R_{\mathrm{ct}}$ decreased from $80.9 \Omega$ for $\mathrm{NiLDH}$ to $11.4 \Omega$. Since the $R_{\mathrm{s}}$ indicates the resistance of the material while $R_{\mathrm{ct}}$ reflects the interfacial charge transfer process between the electrode and electrolyte ions during the charge/discharge process, the lower $R_{\mathrm{s}}$ and $R_{\mathrm{ct}}$ of $\mathrm{NiCuLDH}$ confirm that the incorporation of copper enhances the conductivity of the electrode material meanwhile contributes a faster kinetics of charge transfer in the device. The cyclic stability of both NiLDH and NiCuLDH (7-10) was shown in Fig. S3. Due to the high series resistance and charge transfer resistance, the pristine NiLDH showed a very poor cyclic stability, which only retained $32 \%$ of its original capacitance after 376 cycles. The capacitance is dropped to nearly $0 \mathrm{~F} \mathrm{~g}^{-1}$, which is ascribed to the much increased resistance of the electrode during the cycling test. Compared to $\mathrm{NiLDH}$, the $\mathrm{NiCuLDH}(7-10)$ showed a relatively better cyclic stability with $35 \%$ of its initial capacitance retained even after 500 cycles. Moreover, no sudden drop of the capacitance was observed, further confirming the benefit of $\mathrm{Cu}$ incorporation to enhance the cyclic stability of the material.

In summary, we investigated the effect of $\mathrm{Cu}$-incorporation on the electrochemical performance of $\mathrm{NiLDH}$ nanosheet arrays grown on CFC. Compared to pristine NiLDH material, it is found that the optimum $\mathrm{NiCuLDH}(7-10)$ exhibited superior electrochemical properties including over $50 \%$ enhanced specific capacitance and higher capacitance retention rate $(75 \%$ at $5 \mathrm{~A} \mathrm{~g}^{-1}$ ). These are attributed to the improved kinetics of 
charge transport (lower series resistance) and interfacial charge transfer of the material. This work sheds light on developing high performance supercapacitor using earthabundant material.

\section{Received 24 August 2017; accepted 26 September 2017; published online 16 November 2017}

1 Wang G, Zhang L, Zhang J. A review of electrode materials for electrochemical supercapacitors. Chem Soc Rev, 2012, 41: 797-828

$2 \mathrm{Lu} \mathrm{Z}, \mathrm{Wu} \mathrm{X}$, Jiang $\mathrm{M}$, et al. Transition metal oxides/hydroxides nanoarrays for aqueous electrochemical energy storage systems. Sci China Mater, 2014, 57: 59-69

3 Augustyn V, Simon P, Dunn B. Pseudocapacitive oxide materials for high-rate electrochemical energy storage. Energ Environ Sci, 2014, 7: 1597-1614

4 Bryan AM, Santino LM, Lu Y, et al. Conducting polymers for pseudocapacitive energy storage. Chem Mater, 2016, 28: 59895998

5 Cheng $\mathrm{Y}$, Zhang $\mathrm{H}$, Varanasi $\mathrm{CV}$, et al. Improving the performance of cobalt-nickel hydroxide-based self-supporting electrodes for supercapacitors using accumulative approaches. Energ Environ Sci, 2013, 6: 3314-3321

6 Ling Z, Ren CE, Zhao MQ, et al. Flexible and conductive MXene films and nanocomposites with high capacitance. Proc Natl Acad Sci USA, 2014, 111: 16676-16681

7 Lee YW, Kim BS, Hong J, et al. Hierarchically assembled tubular shell-core-shell heterostructure of hybrid transition metal chalcogenides for high-performance supercapacitors with ultrahigh cyclability. Nano Energ, 2017, 37: 15-23

8 Wang R, Luo Y, Chen Z, et al. The effect of loading density of nickel-cobalt sulfide arrays on their cyclic stability and rate performance for supercapacitors. Sci China Mater, 2016, 59: 629-638

9 Jiao X, Hao Q, Liu $\mathrm{P}$, et al. Facile synthesis of $\mathrm{T}-\mathrm{Nb}_{2} \mathrm{O}_{5}$ nanosheets/ nitrogen and sulfur co-doped graphene for high performance lithium-ion hybrid supercapacitors. Sci China Mater, 2017, doi: 10.1007/s40843-017-9064-6

10 Shao M, Zhang R, Li Z, et al. Layered double hydroxides toward electrochemical energy storage and conversion: design, synthesis and applications. Chem Commun, 2015, 51: 15880-15893

11 Lee JW, Ko JM, Kim JD. Hierarchical microspheres based on $\alpha-\mathrm{Ni}$ $(\mathrm{OH})_{2}$ nanosheets intercalated with different anions: synthesis, anion exchange, and effect of intercalated anions on electrochemical capacitance. J Phys Chem C, 2011, 115: 19445-19454

12 Xie $\mathrm{M}$, Duan $\mathrm{S}$, Shen $\mathrm{Y}$, et al. In-situ-grown $\mathrm{Mg}(\mathrm{OH})_{2}$-derived hybrid $\alpha-\mathrm{Ni}(\mathrm{OH})_{2}$ for highly stable supercapacitor. ACS Energ Lett, 2016, 1: 814-819

13 Wang T, Zhang S, Yan X, et al. 2-Methylimidazole-derived Ni-Co layered double hydroxide nanosheets as high rate capability and high energy density storage material in hybrid supercapacitors. ACS Appl Mater Interfaces, 2017, 9: 15510-15524

14 Huang J, Lei $\mathrm{T}$, Wei $\mathrm{X}$, et al. Effect of Al-doped $\beta-\mathrm{Ni}(\mathrm{OH})_{2}$ nanosheets on electrochemical behaviors for high performance supercapacitor application. J Power Sources, 2013, 232: 370-375

15 Wang Z, Jia W, Jiang M, et al. Microwave-assisted synthesis of layer-by-layer ultra-large and thin NiAl-LDH/RGO nanocomposites and their excellent performance as electrodes. Sci China Mater, 2015, 58: 944-952

16 Mahmood N, Tahir M, Mahmood A, et al. Role of anions on structure and pseudocapacitive performance of metal double hy- droxides decorated with nitrogen-doped graphene. Sci China Mater, 2015, 58: 114-125

17 Chen J, Xu J, Zhou S, et al. Facile and scalable fabrication of threedimensional $\mathrm{Cu}(\mathrm{OH})_{2}$ nanoporous nanorods for solid-state supercapacitors. J Mater Chem A, 2015, 3: 17385-17391

18 He D, Wang G, Liu G, et al. Facile route to achieve mesoporous $\mathrm{Cu}$ $(\mathrm{OH})_{2}$ nanorods on copper foam for high-performance supercapacitor electrode. J Alloys Compd, 2017, 699: 706-712

19 Lei S, Liu Y, Fei L, et al. Commercial Dacron cloth supported Cu $(\mathrm{OH})_{2}$ nanobelt arrays for wearable supercapacitors. J Mater Chem A, 2016, 4: 14781-14788

20 Pramanik A, Maiti S, Mahanty S. Reduced graphene oxide anchored $\mathrm{Cu}(\mathrm{OH})_{2}$ as a high performance electrochemical supercapacitor. Dalton Trans, 2015, 44: 14604-14612

21 Zheng X, Ye Y, Yang Q, et al. Ultrafine nickel-copper carbonate hydroxide hierarchical nanowire networks for high-performance supercapacitor electrodes. Chem Eng J, 2016, 290: 353-360

22 Luan $\mathrm{P}$, Zhang N, Zhou W, et al. Epidermal supercapacitor with high performance. Adv Funct Mater, 2016, 26: 8178-8184

23 Cao J, Chen C, Zhao Q, et al. A flexible nanostructured paper of a reduced graphene oxide-sulfur composite for high-performance lithium-sulfur batteries with unconventional configurations. Adv Mater, 2016, 28: 9629-9636

24 Niu Z, Zhou W, Chen X, et al. Highly compressible and all-solidstate supercapacitors based on nanostructured composite sponge. Adv Mater, 2015, 27: 6002-6008

25 Yang J, Yu C, Fan X, et al. 3D architecture materials made of NiCoAl-LDH nanoplates coupled with $\mathrm{NiCo}$-carbonate hydroxide nanowires grown on flexible graphite paper for asymmetric supercapacitors. Adv Energ Mater, 2014, 4: 1400761

26 Vialat P, Mousty C, Taviot-Gueho C, et al. High-performing monometallic cobalt layered double hydroxide supercapacitor with defined local structure. Adv Funct Mater, 2014, 24: 4831-4842

27 Valente JS, Sanchez-Cantu M, Lima E, et al. Method for large-scale production of multimetallic layered double hydroxides: formation mechanism discernment. Chem Mater, 2009, 21: 5809-5818

28 Wang T, Hao Q, Liu J, et al. High capacitive amorphous barium nickel phosphate nanofibers for electrochemical energy storage. RSC Adv, 2016, 6: 45986-45992

29 Lien CH, Hu CC, Hsu CT, et al. High-performance asymmetric supercapacitor consisting of $\mathrm{Ni}-\mathrm{Co}-\mathrm{Cu}$ oxy-hydroxide nanosheets and activated carbon. Electrochem Commun, 2013, 34: 323-326

30 Li H, Gao Y, Wang C, et al. A simple electrochemical route to access amorphous mixed-metal hydroxides for supercapacitor electrode materials. Adv Energ Mater, 2015, 5: 1401767

31 Lee JH, Lee HJ, Lim SY, et al. Stabilized octahedral frameworks in layered double hydroxides by solid-solution mixing of transition metals. Adv Funct Mater, 2017, 27: 1605225

32 Wang B, Chen JS, Wang Z, et al. Green synthesis of $\mathrm{NiO}$ nanobelts with exceptional pseudo-capacitive properties. Adv Energ Mater, 2012, 2: 1188-1192

33 Nam KW, Kim KB. A study of the preparation of $\mathrm{NiO}_{x}$ electrode via electrochemical route for supercapacitor applications and their charge storage mechanism. J Electrochem Soc, 2002, 149: A346A354

34 Gurav KV, Patil UM, Shin SW, et al. Room temperature chemical synthesis of $\mathrm{Cu}(\mathrm{OH})_{2}$ thin films for supercapacitor application. J Alloys Compd, 2013, 573: 27-31

35 Chen JS, Gui Y, Blackwood DJ. A versatile ionic liquid-assisted approach to synthesize hierarchical structures of $\beta-\mathrm{Ni}(\mathrm{OH})_{2}$ na- 
nosheets for high performance pseudocapacitor. Electrochim Acta, 2016, 188: 863-870

Acknowledgements This work was supported by Queensland University of Technology (QUT) for Postgraduate Research Award scholarships (QUTPRA). The data were obtained at the Central Analytical Research Facility (CARF) operated by the Institute for Future Environments, QUT. Access to CARF is supported by generous funding from the Science and Engineering Faculty (QUT).
Author contributions Wang $\mathrm{T}$ and Wang $\mathrm{H}$ designed the project and the experiments. Wang $\mathrm{T}$ and Zhang $\mathrm{S}$ performed the experiments. Wang $\mathrm{T}$ wrote the paper with support from Wang $\mathrm{H}$. All authors contributed to the general discussion.

Conflict of interest The authors declare that they have no conflict of interest.

Supplementary information Experimental detail and supplementary data are available in the online version of the paper.

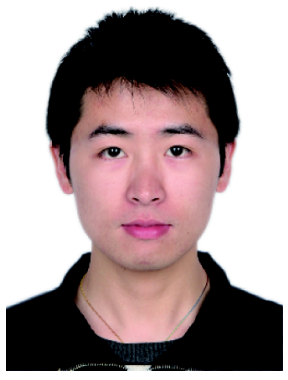

Teng Wang is a PhD candidate at the School of Chemistry, Physics and Mechanical Engineering, Science and Engineering Faculty, Queensland University of Technology, Australia, under the supervision of A/Prof. Hongxia Wang. His current research focuses on the fabrication of high performance nanomaterials for renewable energy conversion and storage devices.

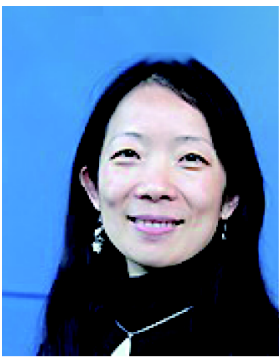

Hongxia Wang is an associate professor and ARC Future Fellow at Queensland University of Technology, Australia. Her main research interest is on development of new routes for low cost solar cells and energy storage devices- work that includes perovskite solar cells, thin film solar cells using earth abundant materials and supercapacitors.

\section{基于镍铜层状双金属氢氧化物纳米片的超级电容器电极及其优异的储能性能}

\section{王腾, 张生利, 王红霞}

摘要 本文通过简便的溶剂热法成功制备了在碳纤维布上原位生长的镍铜层状双金属氢氧化物纳米片阵列. 与纯的氢氧化镍材料相比, 铜的引入极大地增强了其在超级电容器应用方面的各项电化学性能, 包括超过 $50 \%$ 的比电容容量的提高(在充放电电流密度为 $0.5 \mathrm{~A} \mathrm{~g}^{-1}$ 时 其比电容达到 $1953.5 \mathrm{~F} \mathrm{~g}^{-1}$ ) 和更高的倍率性能(在充放电电流密度为 $5 \mathrm{~A} \mathrm{~g}^{-1}$ 时比电容的保持率为 $75 \%$ ). 这些优异的性能是因为镍铜双金属 层状氢氧化物具有更高的导电性和更快的界面电荷迁移率. 本文的研究工作为有效利用地球含量丰富的材料进一步增强基于层状双金属 氢氧化物的超级电容器电极性能提供了新的研究思路和方法. 